\title{
(2) OPEN ACCESS \\ Clinical presentation and improvised management of neonatal pneumothorax in the setting of a low- resource country: Conakry, Guinea
}

\author{
Maria Bea Merscher Alves 다, ${ }^{1}$ N'fanly Conté, ${ }^{2}$ Ibrahima Sory Diallo, ${ }^{2,3}$ \\ Matthias Roth-Kleiner ${ }^{4,5}$
}

${ }^{1}$ Pediatric and Neonatal Intensive Care Unit, Children's Research Center, University Children's Hospital Zurich, University of Zurich, Zurich, Switzerland

${ }^{2}$ Department of Neonatology, Institute of Nutrition and Child Health, Conakry, Guinea ${ }^{3}$ Department of Pediatrics, Gamal Abdel Nasser University of Conakry, Conakry, Guinea ${ }^{4}$ Clinic of Neonatology, Department Woman-MotherChild, CHUV, Lausanne, VD, Switzerland

${ }^{5}$ Association souffle2vie, Epalinges, Switzerland

\section{Correspondence to}

Dr Maria Bea Merscher Alves; bea.merscher@gmail.com

Accepted 14 February 2021

\begin{abstract}
SUMMARY
Two neonates were presented at the Neonatology Department of the Institute of Child Nutrition and Health in Conakry, Guinea, with tension pneumothoraces as confirmed by chest X-ray. They were initially managed with needle thoracentesis but required continuous thoracic drainage. Due to scarce resources in the public health sector, no prepacked and dedicated pleural drainage systems were available as is the case in many developing countries. Therefore, we fabricated an improvised underwater seal drain out of a plastic infusion bottle and a Heimlich valve out of a vicryl fingerstall. Both devices have shown to be effective. Pneumothorax is a common and potentially life-threatening disease in neonates that often requires prompt treatment. This case series demonstrates how tension pneumothorax in two newborns was successfully managed by improvising different chest drainage systems. The depicted techniques shall serve as an instruction manual to healthcare professionals working in low-resource settings and facing similar challenges.
\end{abstract}

\section{BACKGROUND}

The following two case reports illustrate the usage of two different chest drainage systems with the necessity for improvisation and successful management of neonatal pneumothorax in Guinea, a West African country with pronounced restriction in healthcare resources.

This case series shall depict two different ways that thoracic drainage systems can be improvised with simple methods using the most basic healthcare utensils. Hereby, it shall serve as an instruction manual for healthcare professionals working in settings with extremely limited resources.

Pneumothorax is a life-threatening condition that requires immediate intervention. It is a common cause of death among neonates if inappropriately treated. ${ }^{1}$ Birth trauma, aspiration of meconium, underlying lung diseases or positive pressure ventilation can cause pneumothorax in newborns. ${ }^{2}$ Spontaneously occurring pneumothoraces have also been reported. ${ }^{3}$ Most neonates suffering from pneumothorax remain asymptomatic. Chest X-ray is the gold standard for its diagnosis. ${ }^{4}$ Pneumatosis in the thoracic cavity can also be diagnosed by transillumination of the chest using a fibre-optic light or lung ultrasonography. ${ }^{56}$

Small asymptomatic pneumothoraces might only need monitoring; larger and especially tension pneumothoraces require immediate treatment. They can either be managed using needle thoracentesis or inserting a chest tube connected to an underwater seal with continuous suction or a Heimlich valve. ${ }^{7}$ However, in low-income countries, medical diagnosis and treatment can be greatly impeded by a lack of resources and medical devices, such as underwater seal drains.

Guinea is located in Western Africa and ranks among the poorest countries in the world (rank 158 of 182 according to per capita income in 2017). ${ }^{8}$ In 2012, Guinea had an under-five-mortality rate of 93.7 deaths per 1000 live births. The neonatal mortality rate was 33 deaths per 1000 births. ${ }^{9}$ The Institute of Child Nutrition and Health (INSE), located in the capital Conakry, is the only university neonatal clinic in the country, with a catchment area that comprises the whole country. The INSE is a public hospital with very limited resources. Oxygen is only available via oxygen extractors, electricity is scarce during power outages and provided only via solar panels. X-rays have to be performed in an independent institution for radiology that only operates on working days and is not located in the hospital perimeter, therefore requiring neonatal transport. The maternity ward of the INSE has been under renovation for years. Hence, none of the hospitalised patients are born in proximity to the neonatal clinic. The majority of neonates arrive either by taxi, motorcycle or private vehicles and only $4.8 \%$ are transported by ambulance. ${ }^{10}$ This circumstance often leads to long transportation periods worsening the chances of survival of ill neonates.

The Swiss non-profit organisation souffle2vie has been working at the INSE for years in order to reduce neonatal mortality (www.souffle2vie. ch). From February to March 2019 a cohort study was performed, in which all neonates that were

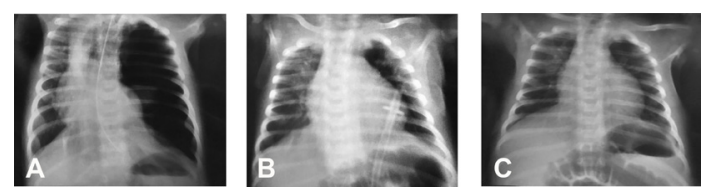

Figure 1 Chest X-ray of case no. 1 in hanging position with left-sided tension pneumothorax. A: At admission with mediastinal shift. B: One day after needle decompression with chest drainage system in situ. C: On day 6 before discharge. 
hospitalised, were registered, including their treatment, diagnoses and outcomes. The two patients were treated in the context of the study entitled 'Assessing Today for a Better Tomorrow: An observational cohort study about quality of care, mortality and morbidity among newborn infants admitted to neonatal intensive care in Guinea'. This study was approved by the 'Comité National d'Ethique pour la Recherche en Santé' (CNERS) with decision under the number: 035/CNERS/19.

\section{CASE PRESENTATION}

\section{Case no. 1}

A 21-day-old previously healthy male neonate was hospitalised in poor general condition with severe respiratory distress and cyanosis. He presented the following vital parameters: respiratory rate $70 \mathrm{cycles} / \mathrm{min}$, heart rate 176 beats/min, body temperature $38.6^{\circ} \mathrm{C}$ and oxygen saturation of $71 \%$. His body weight was $3800 \mathrm{~g}$ with a birth weight reported of $3200 \mathrm{~g}$. Initially, bacterial pneumonia was suspected, leading to antibiotic treatment with 12-hourly ampicillin $100 \mathrm{mg} / \mathrm{kg}$ and 24-hourly gentamicin $5 \mathrm{mg} /$ $\mathrm{kg}$ for a total of five days. Fever ceased on hospitalisation day 2. His oxygenation levels improved slightly under oxygen administration, concentrated by an oxygen extractor (ozone oxygen concentrator) delivered via nasal cannula. Still, dyspnoeic symptoms remained severe with a Silverman Score of $10 / 10 .^{11}$ Asymmetric lung auscultation led to the suspicion of a left-sided pneumothorax. The chest X-ray confirmed a left-sided tension pneumothorax with a mediastinal shift that required immediate needle decompression (figure 1). The largest available needle in the emergency setting was gauge 20 (G20). The chest wall was disinfected and the needle perpendicularly placed in the left second intercostal space in the midclavicular line. The release of air was audible, and the boy's breathing pattern improved immediately with decreasing respiratory rate as well as an increase of the blood oxygenation level from $87 \%$ to $93 \%$. However, when the needle was removed, the symptoms returned quickly. Therefore, the father was asked to search the city's pharmacies for the largest venous catheter available. Approximately 1 hour later, he returned with a G16 intravenous catheter. A gastric tube had been prepared with several holes to serve as a chest tube; however, the smallest available tube was still too large to pass the G16 lumen. Therefore, another needle thoracentesis was

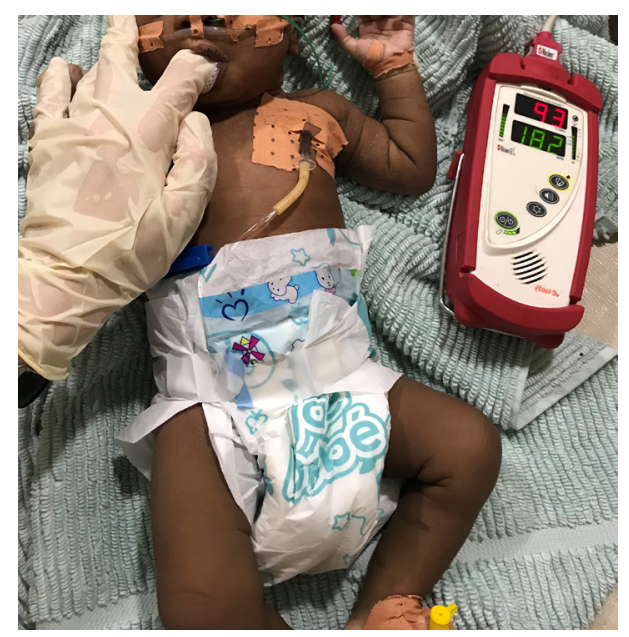

Figure 2 Fixation of the peripheral venous catheter after needle decompression of the chest. Common plasters were used to attach the catheter to the chest wall and to secure the connection between the tubing system and the catheter.

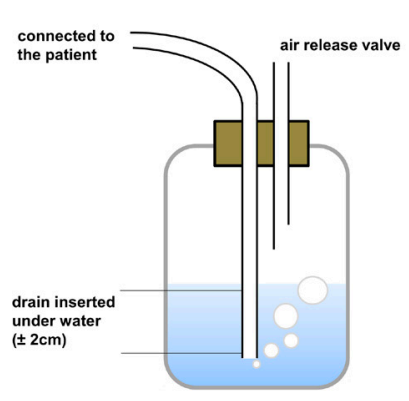

A

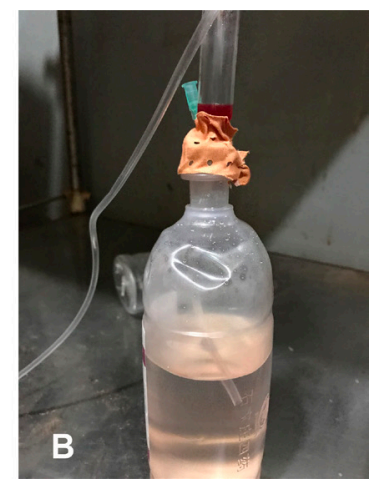

Figure 3 Improvised underwater seal drain. A: Schematic representation of the underwater seal drain. B: An intravenous tubing system was inserted into the intravenous bag and placed into the liquid to ensure a water seal. The system was closed using common plasters and a needle was inserted into the bottle serving as an air release valve. Before placing the drainage system on the floor, it was checked for oscillation in relation with the patient's respiratory movements.

performed, and the G16 venous catheter was left in place and secured with plasters (figure 2). A single bottle underwater seal chest drainage system was improvised using a half-empty intravenous bag, tubing, a needle and plasters (figure 3, online supplemental file 1). The system was checked for oscillation according to the respiratory movements of the patient. The bottle was put on the floor and the child in an anti-Trendelenburg position overnight. To minimise the pain caused by the rigid catheter in the chest cavity, paracetamol, as the only available analgesic, was given intravenously at a dose of $15 \mathrm{mg} / \mathrm{kg}$ every 6 hours. The next day, another chest X-ray was performed showing an almost complete expansion of the left lung with physiologic position of the mediastinum (figure 1). The chest drain was removed and the patient positioned continuously on his left side for another 2 days. During these days, the general condition of the child was satisfactory with no signs of respiratory distress and a Silverman Score of $0 / 10$. The patient was discharged on day 6 with a normal chest X-ray (figure 1). His development has been normal since then with satisfactory weight gain (being exclusively breastfed during the first 6 months), and no other respiratory problems have been reported. The patient is now almost two years old. The aetiology of the pneumothorax remains unclear.

\section{Case no. 2}

A female newborn term infant (Ballard-Score: estimated 40 postgestational weeks) was hospitalised 6 hours after birth due to asphyxia needing cardiopulmonary resuscitation for $30 \mathrm{~min}$ in a public obstetric clinic. She arrived by taxi in a bad general condition with cyanosis, body temperature of $35.9^{\circ} \mathrm{C}$ and heart rate of 100 beats/min. Her body weight was $2500 \mathrm{~g}$. At admission, cervical subcutaneous emphysema was noted. She was warmed externally with a heating lamp and manually ventilated with an Ambu bag due to respiratory insufficiency. After improvement of her spontaneous breathing pattern, oxygen was administered via nasal cannula. Her oxygen saturation was $82 \%$ with and $60 \%$ without supplementary oxygen. The Silverman Score was $6 / 10$ with a respiratory rate of 100 cycles/min and a heart rate of 152 beats/min. Antibiotic treatment was started with ampicillin $100 \mathrm{mg} / \mathrm{kg}$, cefotaxime $100 \mathrm{mg} / \mathrm{kg}$ both two times a day and 24-hourly gentamicin $5 \mathrm{mg} / \mathrm{kg}$. Chest X-ray showed a left-sided pneumothorax, pneumomediastinum and mediastinal shift to the right (figure 4). The largest available venous catheter was 


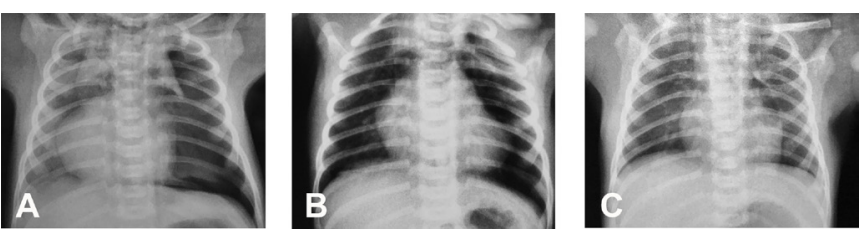

Figure 4 Chest X-ray of case no. 2 in hanging position with left-sided tension pneumothorax, mediastinal shift and pneumomediastinum. (A) At admission. (B) On day 2 showing almost fully expanded lungs. (C) On day 6 with residual pneumomediastinum but without clear radiological signs of pneumonia.

a G18 needle. A cut fingerstall of a vicryl glove was placed on top of the extractible needle serving as an improvised Heimlich valve (figure 5, online supplemental file 2 ). The catheter was then positioned in the left second intercostal space in the midclavicular line after disinfection of the skin. A syringe partially filled with saline solution was connected to the catheter. The bubble test was positive and $15 \mathrm{~mL}$ of air was removed. Unfortunately, the respiratory distress increased after installing the valve and another $15 \mathrm{~mL}$ of air had to be removed from the girl's chest. Therefore, some drops of saline solution were added into the glove to increase the adhesiveness of the material (figure 6). After this measure, the valve was functioning well, with collapse of the glove during inhalation and release of air from the chest during exhalation, with no further deterioration of the patient's breathing pattern. The Silverman Score improved to 3/10, oxygenation saturation levels rose to $97 \%$ under additional oxygen supply and the respiratory rate decreased to 60 cycles/ min with a heart rate of 140 beats/min. Intravenous paracetamol was administered at a dose of $15 \mathrm{mg} / \mathrm{kg}$ every 6 hours, and antibiotic treatment continued for 6 days. The cervical emphysema showed spontaneous regression. Unfortunately, the catheter dislocated and was externalised overnight. However, the chest X-ray on day 2 showed fully expanded lungs (figure 4). On day 4 , the patient developed fever that worsened on day 6 (day 4 : $38.1^{\circ} \mathrm{C}$; day $6: 39.9^{\circ} \mathrm{C}$ ). A follow-up X-ray on day 6 depicted some residual pneumomediastinum but no pneumonia (figure 4). The thick blood smear was free of plasmodium. Lumbar puncture revealed nosocomial gram-positive meningitis which was progressive although the antibiotic treatment was adjusted on day 6, to 8-hourly ampicillin $100 \mathrm{mg} / \mathrm{kg}$ and 24-hourly ceftriaxone $100 \mathrm{mg} / \mathrm{kg}$. The patient finally improved after changing the antibiotic treatment from ampicillin to 8-hourly cloxacillin $100 \mathrm{mg} / \mathrm{kg}$ and while continuing ceftriaxone. The patient was

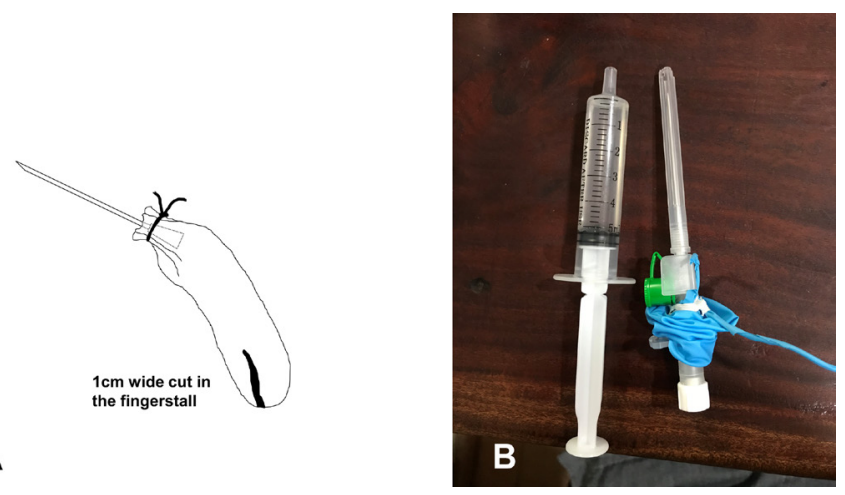

Figure 5 Improvised Heimlich valve using the fingerstall of a vicryl glove. A: Schematic representation of the Heimlich valve. B: The fingerstall was attached to the venous catheter using a common thread.

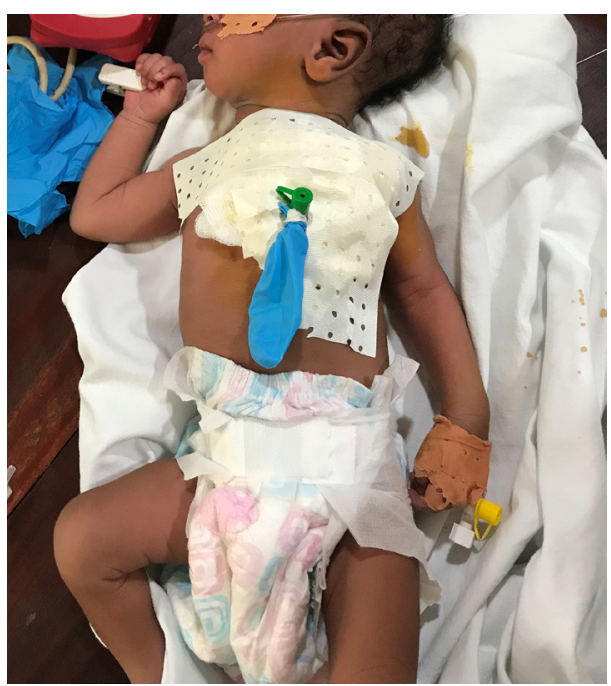

Figure 6 Fixation of the improvised Heimlich valve with common plasters to avoid dislocation. A small quantity of sterile saline was added into the fingerstall to increase the adhesiveness of the material and to improve the sealing mechanism.

discharged in good general condition after ceftriaxone/cloxacillin treatment for 21 days. The patient is now almost two years old and no other health problems have been reported. The cause of pneumothorax in this patient is either birth trauma or most probably cardiopulmonary resuscitation manoeuvres.

\section{OUTCOME AND FOLLOW-UP}

Both patients have survived and fully recovered. The corresponding author is still in touch with both families. Both children had an uneventful further development and are in good medical conditions.

\section{DISCUSSION}

These case reports show that timely diagnosed neonatal pneumothorax can be managed even in settings with limited resources. In developing nations, medical diagnosis and treatment of lifethreatening conditions can be impeded by a lack of access to medical devices. Newborns are a particularly vulnerable population to the delay of adequate treatment. Pneumothorax is a common and potentially life-threatening disease in neonates that often requires prompt thoracentesis and continuous thoracic drainage using equipment, such as underwater seal drains. In healthcare settings where prepacked and dedicated items for specific purpose are not available, these alternative devices have to be manually assembled using accessible parts intended for other usage. A literature search yielded very little practical instructions and guidance on the management of pneumothorax with limited resources and the construction of continuous chest drainage systems, specifically lacking specific data about the application for newborns. ${ }^{12} 13$

Both measures, the drainage with an underwater seal drain and the Heimlich valve, as constructed for the depicted patients have shown to be effective chest drainage methods. ${ }^{14}$ To aid medical doctors and nurses working in similar settings of limited resources, we created detailed instruction manuals with step-bystep pictograms as well as explanations for the assembly of the two thoracic drainage devices (online supplemental files 1 and 2). 
Chest X-rays are useful diagnostic measures, but in critically ill patients may not be necessary for diagnosing and managing pneumothorax. Other diagnostic tests, such as transillumination, have also shown to be helpful and may easily be implemented in low-resource settings. ${ }^{15}$ For the diagnosis of pneumothorax, a careful examination of the chest is crucial. ${ }^{16}$ Absent or distant breathing sounds on one side of the thorax, respiratory distress and vital signs exhibiting tachycardia, desaturation and tachypnoea might be sufficient diagnostic evidence for pneumothorax in newborn infants and should lead to emergency needle chest decompression in critically sick patients. A shift in the apical heart impulse or dislocation of the heart sounds may indicate mediastinal shift due to tension pneumothorax. ${ }^{17}$ Follow-up $\mathrm{X}$-rays help to evaluate the pulmonary expansion and the degree of remaining pneumothorax. Case no. 2 pictured how pneumomediastinum is often associated with pneumothorax. An isolated pneumomediastinum, as seen as a residual in Case no. 2 does usually not need to be treated, but one needs to be aware of an increased risk for a relapse pneumothorax. ${ }^{18}$ Analgesics should be administered before thoracentesis and when a chest tube or, as an alternative, a venous catheter is left in the chest cavity to reduce the evoked pain and to prevent the child from breathing superficially. When working in unsterile conditions, antibiotic coverage should be considered to avoid pneumonia or sepsis. Supportive oxygen should be given as early as possible. ${ }^{19}$ However, administration of pure oxygen to aid reabsorption of pneumothorax has not proven to be effective and shall be avoided. ${ }^{20}$

In conclusion, even in settings with almost non-existing resources, neonatal pneumothorax can be successfully managed if diagnosed timely and treated with a thoracic drainage system.

\section{Learning points}

- Pneumothorax is a life-threatening condition in newborns and can be successfully managed if diagnosed timely and treated with a thoracic drainage system.

- Even in settings with extremely scarce resources, chest drainage systems can be manually assembled by using accessible parts intended for other usages, such as infusion bottles and gloves.

- Schematic representations of improvised thoracic drainage systems, such as provided in the two supplements of this article with step-by-step-instructions of their assembly, may support healthcare workers in low-resource settings in the timely construction of such devices.

Acknowledgements The data presented in this case series was collected during a humanitarian mission funded by soufflezvie and generous private donations. The authors would like to express their gratitude to everyone who has contributed to this mission with a private donation and to the parents for allowing this data to be published. The authors are very grateful to Susanne Staubli, who turned the sketches for the instruction manuals into pictograms, as well as the University Children's Hospital of Zurich for covering the associated costs. The authors would also like to express their appreciation to Roger Glur and Gnouma Charles Komano from rocConakry for their invaluable support. The authors thank Fabian Egli for helping with image editing.

Contributors The corresponding author, Dr MBMA, was responsible for the acquisition of data, the treatment of the patients, the communication with their legal guardians, the writing of the manuscript as well as the sketching of the instruction manuals. Dr NC was involved in the treatment of the patients, especially the assembly of the improvised medical devices for thoracic drainage; he was also responsible for manuscript reviewing. Dr ISD was the clinical supervisor of the project; he was also responsible for manuscript reviewing. Professor MR-K was responsible for manuscript editing and reviewing.

Funding The authors have not declared a specific grant for this research from any funding agency in the public, commercial or not-for-profit sectors.

Competing interests None declared.

Patient consent for publication Parental/guardian consent obtained.

Provenance and peer review Not commissioned; externally peer reviewed.

Supplemental material This content has been supplied by the author(s). It has not been vetted by BMJ Publishing Group Limited (BMJ) and may not have been peer-reviewed. Any opinions or recommendations discussed are solely those of the author(s) and are not endorsed by BMJ. BMJ disclaims all liability and responsibility arising from any reliance placed on the content. Where the content includes any translated material, BMJ does not warrant the accuracy and reliability of the translations (including but not limited to local regulations, clinical guidelines, terminology, drug names and drug dosages), and is not responsible for any error and/or omissions arising from translation and adaptation or otherwise.

Open access This is an open access article distributed in accordance with the Creative Commons Attribution Non Commercial (CC BY-NC 4.0) license, which permits others to distribute, remix, adapt, build upon this work non-commercially, and license their derivative works on different terms, provided the original work is properly cited and the use is non-commercial. See: http://creativecommons.org/ licenses/by-nc/4.0/.

\section{ORCID iD}

Maria Bea Merscher Alves http://orcid.org/0000-0002-6953-4225

\section{REFERENCES}

1 Duong HH, Mirea L, Shah PS, et al. Pneumothorax in neonates: trends, predictors and outcomes. J Neonatal Perinatal Med 2014;7:29-38.

2 Wyatt TH. Pneumothorax in the neonate. J Obstet Gynecol Neonatal Nurs 1995;24:211-6.

3 Arora K, Panda SS, Das RR. Primary spontaneous bilateral pneumothorax in a neonate. APSP J Case Rep 2014;5:31.

4 Parekh UR, Maguire AM, Emery J, et al. Pneumothorax in neonates: complication during endotracheal intubation, diagnosis, and management. J Anaesthesio/ Clin Pharmacol 2016:32:397-9.

5 Kuhns LR, Bednarek FJ, Wyman ML, et al. Diagnosis of pneumothorax or pneumomediastinum in the neonate by transillumination. Pediatrics 1975;56:355-60.

6 Volpicelli G. Sonographic diagnosis of pneumothorax. Intensive Care Med 2011;37:224-32.

7 Bruschettini M, Romantsik 0, Zappettini S, et al. Needle aspiration versus intercostal tube drainage for pneumothorax in the newborn. Cochrane Database Syst Rev 2019;44.

8 World Bank. Gdp per capita, ppp (current international \$); world development indicators database, 2018. Available: https://data.worldbank.org/indicator/NY.GDP. PCAP.PP.CD

9 UNICEF. MICS - Multiple Indicator Cluster Surveys 2012, 2012. Available: http://mics. unicef.org/

10 Sory DI, Sory D, N'fanly C, et al. Neonatal mortality associated with the referral of low birth weight newborns to the Institute of child nutrition and health (INSE). Open $J$ Pediatr 2019;09:287-95.

11 Silverman WA, Andersen DH. A controlled clinical trial of effects of water mist on obstructive respiratory signs, death rate and necropsy findings among premature infants. Pediatrics 1956;17:1-10.

12 Vinson ED. Improvised chest tube drain for decompression of an acute tension pneumothorax. Mil Med 2004;169:403-5.

13 Flores-Franco RA. Improvised chest tube valve for intra-hospital patient transportation. Indian J Chest Dis Allied Sci 2010;52:175-6.

14 Lackey DA, Ukrainski CT, Taber P. The management of tension pneumothorax in the neonate using the Heimlich flutter valve. J Pediatr 1974;84:438-40.

15 Razak A, Mohanty PK, Venkatesh H. Anteromedial pneumothorax in a neonate: 'The diagnostic dilemma' and the importance of clinical signs. Case Reports 2014; 2014:bcr2013202487.

16 Kim SK, Kim WH. Tension pneumothorax in a newborn after cesarean-section delivery -A case report-. Korean J Anesthesiol 2010;59:420-4.

17 Chernick V, Avery ME. Spontaneous alveolar rupture at birth. Pediatrics 1963:32:816-24

18 Pfenninger J, Bossi E, Biesold J, et al. Treatment of pneumothorax, pneumopericardium and pneumomediastinum. Helv Paediatr Acta 1982;37:353-60.

19 Reuter S, Moser C, Baack M. Respiratory distress in the newborn. Pediatr Rev 2014;35:417-29.

20 Clark SD, Saker F, Schneeberger MT, et al. Administration of 100\% oxygen does not hasten resolution of symptomatic spontaneous pneumothorax in neonates. J Perinatol 2014;34:528-31. 
Copyright 2021 BMJ Publishing Group. All rights reserved. For permission to reuse any of this content visit https://www.bmj.com/company/products-services/rights-and-licensing/permissions/

BMJ Case Report Fellows may re-use this article for personal use and teaching without any further permission.

Become a Fellow of BMJ Case Reports today and you can:

- Submit as many cases as you like

Enjoy fast sympathetic peer review and rapid publication of accepted articles

Access all the published articles

Re-use any of the published material for personal use and teaching without further permission

Customer Service

If you have any further queries about your subscription, please contact our customer services team on +44 (0) 2071111105 or via email at support@bmj.com.

Visit casereports.bmj.com for more articles like this and to become a Fellow 